\title{
Are cardiac patients in Saudi Arabia provided adequate instructions when they should not drive?
}

\author{
Rami M. Abazid ${ }^{2}$, Mohammed Ewid ${ }^{2}$, Hossam Sherif3, Osama A. Smettei ${ }^{4}$, Abdul Salim Khan ${ }^{5}$, Abdullah A. Altorbag ${ }^{6}$, \\ Mohammad F. Alharbi ${ }^{6}$, Abdulrahman N. Aljaber ${ }^{6}$, Suliman M. Alharbi ${ }^{6}$, Nora A. Altorbak ${ }^{6}$, Sarah A. Altorbak ${ }^{6}$, \\ Ahmad Almeman \\ ${ }^{1}$ Department of Nuclear Medicine, London Health Sciences Centre, London, Canada, Department of Cardiac Imaging, Prince Sultan \\ Cardiac Center Qassim PSCCQ, Buraydah, El Qassim, Saudi Arabia, ${ }^{2}$ Faculty of Medicine, Suliman Al Rajhi Colleges, Buraydah, El Qassim, \\ Saudi Arabia, Internal Medicine Department, Faculty of Medicine, Cairo University, Egypt, ${ }^{3}$ Faculty of Medicine, Suliman Al Rajhi Colleges, \\ Buraydah, El Qassim, Saudi Arabia, Critical Care Medicine Department, Faculty of Medicine, Cairo University, Egypt, ${ }^{4}$ Department of Cardiac \\ Imaging, Prince Sultan Cardiac Center Qassim PSCCQ, Buraydah, El Qassim, Saudi Arabia, ${ }^{5}$ Department of Cardiology, Prince Mohammad \\ Bin Abdulaziz Hospital, Riyadh, Saudi Arabia, ${ }^{6}$ Department of medicine, College of Medicine, Qassim University, El Qassim, Saudi Arabia, \\ ${ }^{7}$ Department of Pharmacology, College of Medicine, Qassim University, El Qassim, Saudi Arabia
}

\begin{tabular}{|c|}
\hline Access this article online \\
\hline Website: www.avicennajmed.com \\
\hline DOI: 10.4103/ajm.AJM_69_19 \\
\hline Quick Response Code: \\
口 \\
\hline \\
\hline
\end{tabular}

\begin{abstract}
Objective: Driving capability can be significantly affected by different heath disorders; cardiovascular diseases (CVDs) should be considered when assessing patients for medical fitness to drive (MFTD). The aim of this study was to evaluate the awareness of Saudi patients about driving recommendations and to assess the incidence of motor vehicle accidents (MVAs) among cardiac patients. Materials and Methods: We conducted a cross-sectional survey-based study. Male patients diagnosed with CVDs and who were visiting outpatient departments were invited to complete a questionnaire regarding their awareness of driving recommendations. Patients' demographics, clinical diagnosis, echocardiography parameters, and time-to-CVD diagnosis were all obtained from the patients' medical records. Women were excluded because it was illegal for women to drive in Saudi Arabia during the study period. Results: In total, 800 men were included, with a mean age of $54 \pm 12$ years. Driving counseling had been provided to 241 participants $(30 \%)$. Of these, $207(25 \%)$ were advised not to drive for a period of between one week and six months. Five percent of the patients had a history of MVAs during the follow-up period of $6.2 \pm 4$ years. We found that the presence of a dyspnea $\geq 2$, according to the New York Heart Association (NYHA), and a history of loss of consciousness (syncope/pre-syncope) were significantly associated with accidents ( $46 \%$ vs. $20 \%, P<0.0001$ and $41 \%$ vs. $10 \%, P<0.0001$, respectively). Conclusion: Patient-physician discussion about MFTD was only performed with $30 \%$ of the patients with CVDs in Saudi Arabia. Dyspnea NYHA class $\geq 2$ or a prior history of syncope were significantly associated with the incidence of MVAs.
\end{abstract}

Key words: Cardiovascular diseases, medical fitness to drive, motor vehicle accidents, Saudi Arabia

\section{INTRODUCTION}

The driving of vehicles is considered an important mode of transportation, public, and private worldwide. In order to drive safely, drivers should have average motor, visual, and cognitive functions. ${ }^{[1]}$ Multiple heath disorders can affect

Address for correspondence: Rami M. Abazid, Department of Nuclear Medicine, London Health Sciences Centre, 800 Commissioners Road East, PO Box 5010, London, ON, N6A 5W9, Canada.

E-mail: ramiabazid@yahoo.com driving capacity and the ability to drive safely. In particular, cardiovascular diseases (CVDs) can result in impairment/ loss of consciousness because of syncope, pre-syncope,

This is an open access journal, and articles are distributed under the terms of the Creative Commons Attribution-NonCommercial-ShareAlike 4.0 License, which allows others to remix, tweak, and build upon the work non-commercially, as long as appropriate credit is given and the new creations are licensed under the identical terms.

For reprints contact: reprints@medknow.com

Cite this article as: Abazid RM, Ewid M, Sherif H, Smettei OA, Salim Khan A, Altorbag AA, et al. Are cardiac patients in Saudi Arabia provided adequate instructions when they should not drive? Avicenna J Med 2019;9:148-53. 
and faintness, which have a remarkable impact on medical fitness to drive (MFTD) and should be carefully taken into account when assessing the capability of cardiac patients to drive vehicles. ${ }^{[2,3]}$ Importantly, a temporary or permanent driving restriction should be considered in all symptomatic patients with CVD based on the severity of their symptoms and the reversibility of the condition. ${ }^{[4,5]}$ Most western countries have regulatory bodies that are responsible for providing regulations to health-care workers and to set proper guidelines for assessment of MFTD, cessation periods, and the requirements for resuming driving; ${ }^{[6-8]}$ enforcement of these guidelines has been shown to result in a $45 \%$ reduction in motor vehicle accidents (MVAs) related to drivers with medical conditions. ${ }^{[9]}$

MVAs account for $11.7 \%$ of the total mortalities in Saudi Arabia and were consistently reported as the third leading cause of death between 2005 and 2010. ${ }^{[10]}$ Several studies worldwide have shown that patients with CVD are at a higher risk for MVA that put them, their families, and the public in great danger. ${ }^{[11-13]}$ As similar studies have not been conducted in the Kingdom of Saudi Arabia, the aim of this study was to evaluate the awareness of such patients about the driving recommendations and regulations, in particular those related to CVDs, and to assess the incidence of MVA among patients with CVD in Saudi Arabia.

The primary objective of this study is to evaluate the adherence to driving restriction guidelines of patients visiting a tertiary cardiac care center in the central province of Saudi Arabia.

\section{MATERIALS AND METHODS}

This is a cross-sectional observational descriptive study, based on a survey administered between February and April 2018, and the data were collected primarily by a questionnaire. After providing written consent, all male patients who were older than 18 years, who had been diagnosed as having a CVD, and who were visiting an outpatient department during the study period were included and were invited to complete the study questionnaire, which contains 12 questions regarding driving caution. In addition, we specifically asked the participants if they had received any recommendations regarding MFTD based on their diseases by their treating physicians.

The participants' demographics, drug history, and clinical diagnosis were all obtained from the patients' medical records, and included any history of coronary artery disease, revascularization, cardiomyopathy, arrhythmias, device implantation, and echocardiography parameters (ejection fraction and the presence of significant valvular heart disease); in addition, we reported cardiac symptoms such as chest pain, palpitation, syncope (loss of consciousness), pre-syncope (impairment of consciousness), and dyspnea New York Heart Association (NYHA) class (Class I, no shortness of breath with ordinary physical activity; Class II, mild dyspnea with ordinary physical activity; and Classes III and IV, dyspnea with minimal physical activities and at rest, respectively). Women were excluded because it was illegal for women to drive in Saudi Arabia during the study period; additionally, those patients who refused to sign the study's informed consent form were excluded. The study protocol had been approved by the regional and institutional ethical committees.

\section{Survey questions}

The survey questions are all in Arabic and were translated into English for the sake of the publication process. The responses were obtained and documented by trained physicians. Validation of the questionnaire had been constructed in five phases:

Phase I: Diseases and symptoms that increase the risk of MVAs were put together based on international driving guidelines. ${ }^{[1]}$

Phase II: Questions were selected by expert cardiologists to detect whether the accidents resulted from symptoms related to CVD while driving the vehicles.

Phase III: Contents were validated through a pilot test among a group of experts.

Phase IV: Contents were validated through a pilot test among a group of participants.

Phase V: Reliability was tested using Cronbach's a coefficient.

\section{Survey validation}

For Phases I and II, an extensive literature review was conducted on driving-related causality and international guidelines. The appropriate items were prepared for the questionnaire and included the risk factors. A group of experts conducted these phases, including three cardiologists, a clinical pharmacist, a nurse, and a socialist. All questionnaire items were amended accordingly to be short and focused on MVAs related to cardiac events. The first part of the survey asked about socio-demographics, and the second part was for the patients. For Phases III and IV, the survey was tested with eight health-care providers (four cardiologists and four cardiac care unit nurses) and 15 patients with CVDs to assess the content validity. The entire pilot study was met with positive responses, and participants expressed that the survey questions were easy 
to understand. Five patients requested that the language in questions 4 and 5 be amended so that it could be more easily understood; those questions were edited accordingly. In Phase $\mathrm{V}$, the amended survey was administered to 50 patients, and showed a good internal consistency with a Cronbach's $\alpha$ of $0.75-0.85$.

\section{Statistical analysis}

Quantitative variables were expressed as means \pm standard deviations, and categorical variables were expressed as frequencies. A two-sample $t$-test was used for normally distributed continuous variables, and a chi-squared test was run for categorical variables. A value of $P<0.05$ was considered statistically significant. All statistical analyses were performed using Statistical Package for the Social Sciences software for Windows (version 19.0; SPSS, Chicago, IL).

\section{RESULTS}

\section{Baseline characteristics}

A total of 800 men participated in this study. The majority of the participants were Saudi (95\%), and the mean age was

\begin{tabular}{|c|c|}
\hline \multicolumn{2}{|l|}{ Baseline characteristics } \\
\hline Diagnosis & Number (\%) \\
\hline Diabetes mellitus, $n(\%)$ & $392(54)$ \\
\hline Hypertension, $n(\%)$ & $526(69)$ \\
\hline Family history of coronary artery disease, $n(\%)$ & $80(\mathrm{II})$ \\
\hline Smoking, $n(\%)$ & $150(22)$ \\
\hline Dyslipidemia, $n(\%)$ & $379(54)$ \\
\hline Left bundle branch block, $n(\%)$ & $27(3)$ \\
\hline $\mathrm{EF} \%($ mean $\pm \mathrm{SD})$ & $(45 \pm 13)$ \\
\hline NYHA Class I & $138(20)$ \\
\hline NYHA Class II & $82(10)$ \\
\hline NYHA Class III & $58(7)$ \\
\hline NYHA Class IV & $30(5)$ \\
\hline \multicolumn{2}{|l|}{ Cardiovascular diseases } \\
\hline Diagnosis & Number (\%) \\
\hline Chronic stable angina & $371(46)$ \\
\hline $\begin{array}{l}\text { History unstable angina/non-ST-segment elevation } \\
\text { myocardial infarction }\end{array}$ & $177(22)$ \\
\hline History of ST-segment elevation myocardial infarction & $161(20)$ \\
\hline Ischemic cardiomyopathy & $183(23)$ \\
\hline Non-ischemic cardiomyopathy & $38(6)$ \\
\hline Previous percutaneous coronary intervention & $274(39)$ \\
\hline Previous coronary artery bypass grafting & $83(12)$ \\
\hline Atrial fibrillation & $59(7)$ \\
\hline Supraventricular tachycardia & $10(1)$ \\
\hline Ventricular tachycardia & $4(0.5)$ \\
\hline Other arrhythmias & $4(0.5)$ \\
\hline Implanted cardioversion defibrillator & $8(1)$ \\
\hline Permanent pacemaker & $5(0.5)$ \\
\hline Congenital heart disease & $12(2)$ \\
\hline Hypertrophic cardiomyopathy & $13(2)$ \\
\hline Previous history of catheter ablation & $7(I)$ \\
\hline Complete heart block & $5(0.5)$ \\
\hline Aortic aneurysm & $3(0.5)$ \\
\hline History of aortic dissection & $2(0.25)$ \\
\hline Wolff-Parkinson-White syndrome & I $(0.1)$ \\
\hline Long QT syndrome & $\mathrm{I}(0.1)$ \\
\hline
\end{tabular}

$54 \pm 12$ years. We found that 221 (27.6\%) of the participants had ejection fraction $<40 \%$. Of the total, $526(66 \%)$ had a history of a previous hospitalization. The most common CVDs across the study population were chronic stable angina (371 [46\%]) followed by a history of acute coronary syndrome (338 [42\%]). Other CVD distributions are presented in Table 1.

\section{Survey responses}

We found that $95 \%$ of the patients were non-commercial car drivers, and 5\% were drivers of large cars such as trucks. The mean time between disease diagnosis and conducting the survey was about $6.2 \pm 4$ years. The majority of patients, $70 \%$, denied having received any counseling or taking part in any discussions about driving during the hospitalization period or clinic follow-ups. However, driving counseling had been provided to 241 participants (30\%), of which 207 (25\%) were advised not to drive for a period of between one week and six months. Three patients had been permanently forbidden to drive (two patients by ophthalmologists and one by a cardiologist). The details of participant responses to the survey questions are listed in Table 2.

\section{Vehicle accidents}

We found that 39 of 800 ( $5 \%$ of the patients) had a history of car accidents during the follow-up period. Twenty of those 39 (51\%) were preceded by cardiac symptoms (nine [23\%] patients had experienced syncope and/or pre-syncope, six [15.5\%] patients had chest pain, four [10\%] patients had palpitations, and one [2.5\%] patient had dyspnea). We found that the presence of a dyspnea NYHA class $\geq 2$ and a history of syncope/pre-syncope were significantly associated with accidents ( $46 \%$ vs. $20 \%, P<0.0001$ and $41 \%$ vs. $10 \%$, $P<0.0001$, respectively) [Figure 1 and Table 3].

\section{DISCUSSION}

In this study, we investigated the degree of awareness to MFTD recommendations in patients with CVDs and how often they were counseled in this regard by cardiologists; we found that $70 \%$ of patients denied being asked about MFTD during hospitalization and/or outpatient clinic follow-ups. Furthermore, we found that MVAs were significantly more common in patients who had dyspnea NYHA class $\geq 2$ or a prior history of syncope.

MVAs have been reported as the third leading cause of death and account for $11.7 \%$ of the total mortalities in Saudi Arabia. ${ }^{[10]}$ In addition, a report from the World Health Organization (WHO) in 2013 stated that Saudi Arabia had the highest MVA fatality rate among countries 


\begin{tabular}{|c|c|}
\hline Question & Number of answers (\%) \\
\hline What is the vehicle type? & $\begin{array}{l}\text { Small car: } 95 \\
\text { Large vehicle: } 5\end{array}$ \\
\hline Where you instructed about driving by your physician in the hospital or the clinic? & Yes: 235 (29) \\
\hline Were you instructed by your cardiologist not to drive? & Yes: 207 (25) \\
\hline For how long? & Period: days to months \\
\hline Were you instructed not to drive by any other physician? & Yes: $6(1)$ \\
\hline For how long? & Period: days to months \\
\hline \multirow[t]{4}{*}{ What is the specialty of the physician who instructed you? } & Neurologists: I patient \\
\hline & Endocrinologists: I patient \\
\hline & Ophthalmologists: 3 patients \\
\hline & Others: Orthopedics: I patient \\
\hline Were you instructed never to drive again? & Yes: $3(0.5)$ \\
\hline Did you ever lose consciousness, or nearly lose consciousness, after being diagnosed with a cardiac disease? & Yes: 91 (II) \\
\hline Did you ever have an accident while driving after being diagnosed with a cardiac disease? & Yes: $39(5)$ \\
\hline If you had an accident, did you lose or nearly lose your consciousness immediately preceding the collision? & Yes: 9 (I.I) \\
\hline If you had an accident, did you experience chest pain immediately preceding the collision? & Yes: 6 (I5.5) \\
\hline If you had an accident, did you experience palpitation immediately preceding the collision? & Yes: $4(10)$ \\
\hline If you had an accident, did you experience dyspnea immediately preceding the collision? & Yes: I (2.5) \\
\hline
\end{tabular}

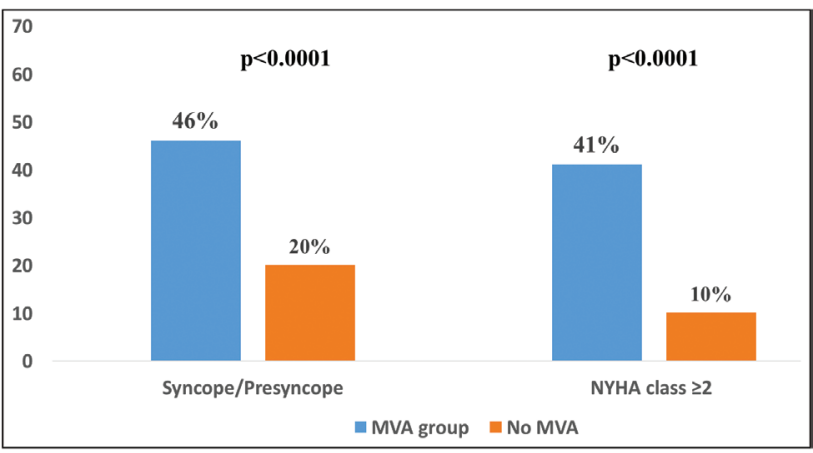

Figure 1: Comparison between patients with and without motor vehicle accident (MVA) regarding symptoms preceding the accident

with high incomes, ${ }^{[14]}$ reaching 24 fatalities per 100,000 people, 2.4 times higher than the rate in the United States. ${ }^{[15]}$ Importantly, there are five road safety pillars identified by the WHO: road infrastructure, road safety policy, safe vehicles, post-crash care, and road users' safe behavior. Of note, road users' poor behavior has a detrimental impact on the incidence and fatality rate of MVAs, and it has been reported as the most common cause of MVAs in different regions across Saudi Arabia. ${ }^{[16]}$ Other road user-related factors that influence MVAs are health abnormalities affecting cognitive, vision, or motor functions; of particular interest for this study are neurological and CVDs that result in impairment of consciousness levels due to drowsiness, syncope, or presyncope.

Our 2019 survey of cardiologists' awareness of the international driving guidelines showed that $70 \%$ were aware of them ${ }^{[17]}$; however, in this study, only $30 \%$ of the patients were counseled by their cardiologists about MFTD. This contradiction reflects an insufficiency in patientphysician communications and a low level of discussion regarding MFTD. Thus, further efforts should be undertaken to transmit physicians' knowledge and information to patients through efficient discussion about MFTD, risks, and driving cessation periods; in this regards, we suggest providing a checklist of discharge recommendations that includes counseling about driving, cessation periods, and the need for any further testing before providing patients with permission to drive.

A recent study conducted by Alkharboush et al. ${ }^{[4]}$ in Saudi Arabia showed similar results to ours, in which only $15 \%$ of primary care physicians had questioned their patients about MFTD, whereas the rest believed that this is a responsibility belonging either to the patients or the local traffic authorities.

The existing international driving agencies and the published guidelines recommend risk assessment for patients with diabetes mellitus and the possibilities of developing hypoglycemic or hyperglycemic attacks, which require MFTD advice; of note, our study population also has a high prevalence of diabetes (54\%). Nevertheless, less than $1 \%$ of the study cohort had been educated regarding MFTD by either endocrinologists or general practitioners, which highlights the need for further studies to assess the MFTD awareness among health-care providers of different medical specialties.

It is interesting to note that accident rates and consequences (such as property damage, public injuries, and fatality rate) are significantly higher in male drivers compared with women $^{[18]}$; however, no women were included in our study, as it was illegal for women to drive in Saudi Arabia during the study period. However, with the recent legislation 


\begin{tabular}{|c|c|c|c|}
\hline & Patients with MVA n (\%) & Patients with no MVA n (\%) & $P$-value \\
\hline Number (\%) & $39(5 \%)$ & $76 I(95 \%)$ & \\
\hline Years & 52 years \pm 14 & 55 years \pm 11 & 0.1 \\
\hline Diabetes mellitus & $21(54 \%)$ & 371 (49\%) & 0.055 \\
\hline Hypertension & 27 (69\%) & 499 (66\%) & 0.7 \\
\hline Previous percutaneous coronary intervention & 17 (44\%) & $257(34 \%)$ & 0.2 \\
\hline Previous coronary artery bypass graft surgery & $3(8 \%)$ & $80(11 \%)$ & 0.7 \\
\hline Atrial fibrillation & $3(8 \%)$ & $56(7 \%)$ & 0.8 \\
\hline Supraventricular tachycardia & I (3\%) & $9(1 \%)$ & 0.4 \\
\hline Ventricular tachycardia & $0(0 \%)$ & $4(0.5 \%)$ & 0.8 \\
\hline Ejection fraction $<40 \%$ & $21(21 \%)$ & $213(28 \%)$ & 0.3 \\
\hline $\mathrm{NYHA} \geq 2$ & $18(46 \%)$ & 152 (20\%) & $<0.0001$ \\
\hline Previous history of syncope & $16(41 \%)$ & $75(10 \%)$ & $<0.0001$ \\
\hline
\end{tabular}

allowing women to drive, further studies that include women should be conducted.

Our study is important in that it targeted road users, investigating their perception about the effect of their CVDs on performing safe vehicle driving; in addition, it highlights the importance of the formulation and implementing of strict guidelines about MFTD in Saudi Arabia through collaboration between the Ministry of Health, the Saudi Commission for Health Specialties, the Saudi Heart Association, and the national traffic authorities. This would be similar to the current guidelines in Canada. ${ }^{[19]}$

Our study has many limitations: it is a single-center analysis, only patients engaging in follow-ups at a cardiology clinic were included, whereas no other medical specialties (such as neurology or endocrinology) were included, it only included men, and MVAs in our study may not be fully represented because accidents that resulted in death or serious damage would not be reported because of missed clinic follow-ups.

\section{CONCLUSION}

We found that only $30 \%$ of the patients with CVDs had been counseled by physicians about MFTD, and MVAs were significantly more common in patients who had dyspnea NYHA class $\geq 2$ or a prior history of syncope. Legislation and clinical implementation of MFTD guidelines is warranted in Saudi Arabia.

\section{Financial support and sponsorship}

Nil.

\section{Conflicts of interest}

There are no conflicts of interest.

\section{REFERENCES}

1. UK Government Digital Services. Assessing Fitness to Drive: A Guide for Medical Professionals: Advice for Medical Professionals for Assessing Fitness to Drive. Driver and Vehicle Licensing Agency. Available from: (https://www.gov.uk/guidance/assessing-fitness-to-drive-a-guide-formedical-professionals). [Last accessed on 20 Feb. 2019].

2. Lee JD. Fifty years of driving safety research. Hum Factors: J Hum Factors Ergonomics Soc 2008;50:521-8.

3. Moon S, Ranchet M, Tant M, Akinwuntan AE, Devos H. Comparison of unsafe driving across medical conditions. Mayo Clin Proc 2017;92:1341-50.

4. Alkharboush GA, Al Rashed FA, Saleem AH, Alnajashi IS, Almeneessier AS, Olaish AH, et al. Assessment of patients' medical fitness to drive by primary care physicians: A cross-sectional study. Traffic Inj Prev 2017;18:488-92.

5. Mansuri FA, Al-Zalabani AH, Zalat MM, Qabshawi RI. Road safety and road traffic accidents in Saudi Arabia: A systematic review of existing evidence. Saudi Med J 2015;36:418-24.

6. Hradec J, Táborský M, Toušek F, Skalická H. Assessing cardiac patients for fitness to drive motor vehicles: Expert consensus statement of the Czech Society of Cardiology—2012 update. Cor et Vasa 2013;55:e217-24.

7. Molnar FJ, Byszewski AM, Marshall SC, Man-Son-Hing M. Inoffice evaluation of medical fitness to drive: Practical approaches for assessing older people. Can Fam Physician 2005;51: 372-9.

8. Hogan DB. Which older patients are competent to drive? Approaches to office-based assessment. Can Fam Physician 2005;51:362-368.

9. Redelmeier DA, Yarnell CJ, Thiruchelvam D, Tibshirani RJ. Physicians' warnings for unfit drivers and the risk of trauma from road crashes. N Engl J Med 2012;367:1228-36.

10. Memish ZA, Jaber S, Mokdad AH, AlMazroa MA, Murray CJL, Al Rabeeah AA, Saudi Burden of Disease Collaborators. Burden of disease, injuries, and risk factors in the Kingdom of Saudi Arabia, 1990-2010. Prevent Chron Dis 2014;11:E169.

11. Meuser TM, Carr DB, Ulfarsson GF. Motor-vehicle crash history and licensing outcomes for older drivers reported as medically impaired in Missouri. Accid Anal Prev 2009;41:246-52.

12. Redelmeier DA, Kenshole AB, Ray JG. Motor vehicle crashes in diabetic patients with tight glycemic control: A population-based case control analysis. PLoS Med 2009;6:e1000192.

13. Antin JF, Lockhart TE, Stanley LM, Guo F. Comparing the impairment profiles of older drivers and non-drivers: Toward the development of a fitness-to-drive model. Saf Sci 2012;50:333-41.

14. World Health Organization. Global Status Report on Road Safety. Geneva, Switzerland: World Health Organization; 2013. Available 
from: http://www.who.int/violence injury prevention/road safety status/2013/en. [Last accessed on 14 Feb. 2019].

15. The Cooperation Council for the Arab States of the Gulf (GCC). Statistics Department; 2012. Available from: http://www.gcc-sg.org/eng. [Last accessed on 13 Jan. 2019].

16. World Health Organization. A Decade of Action for Road Safety: A Brief Planning Document. Geneva, Switzerland: World Health Organization; 2011. Available from: www.who.int/roadsafety/Decade_of_action.pdf. [Last accessed on 24 Jan. 2019].
17. Abazid RM, Almeman A, Sakr H, Eldesoky AF, Eissa HM, Alharbi TH, et al. Awareness of fitness to drive among cardiologists in Saudi Arabia. Saudi Med J 2019;40:93-6.

18. Al-Balbissi AH. Role of gender in road accidents. Traffic Inj Prev 2003;4:64-73.

19. Dow J, Simpson C, Molnar F, Gillespie I, Bergeron D, Brook E, et al., editors. CMA Driver's Guide: Determining Medical Fitness to Operate Motor Vehicles. 9th ed. Ottawa, ON: Canadian Medical Association; 2019. 